\title{
Secondary prevention treatment after acute stroke in older South Asian, Chinese and other Canadians: a retrospective data analysis
}

\author{
Nadia A. Khan MD MSc, Finlay A. McAlister MD MPH, Louise Pilote MD PhD, Anita Palepu MD MPH, \\ Hude Quan PhD, Michael D. Hill MD MSc, Jiming Fang PhD, Moira K. Kapral MD MSc
}

Abstract

Background: Little is known about whether there are differences in medication use between older patients of Chinese descent, those of South Asian descent and other Canadian patients after acute ischemic or primary intracerebral hemorrhagic stroke. The aim of this population-based study was to evaluate potential ethnic differences in secondary prevention pharmacotherapy after acute stroke.

Methods: Using health administrative data, we conducted a retrospective analysis of all patients aged 66 years or more admitted to hospital with acute stroke in Ontario (1997-2011) and British Columbia (1997-2009). We compared prescriptions filled for statins, warfarin, any antihypertensive agent, the recommended combination of angiotensin-converting-enzyme (ACE) inhibitor and diuretic, and the combination of ACE inhibitor, diuretic and statin within 1 year after ischemic or primary intracerebral hemorrhagic stroke.

Results: There were 118362 patients with acute stroke (3430 Chinese, 2075 South Asian and 112857 other Canadians). Among those with ischemic stroke $(n=108699)$, Chinese patients were less likely than other Canadian patients to fill prescriptions for the combination of ACE inhibitor, diuretic and statin (adjusted odds ratio [OR] 0.64 [95\% confidence interval (Cl) $0.55-0.74$ ]) and, in those with atrial fibrillation, for warfarin (adjusted OR 0.75 [95\% $\mathrm{Cl} 0.59-0.95]$ ). There were no differences in filling of prescriptions for antihypertensive therapy overall between the 3 groups. Among patients with intracerebral hemorrhagic stroke $(n=9663)$, Chinese patients were less likely than other Canadian patients to fill prescriptions for the combination of ACE inhibitor and diuretic (adjusted OR 0.51 [95\% Cl 0.38-0.69]), and South Asians were more likely than other Canadian patients to fill prescriptions for any antihypertensive agent (adjusted OR 1.73 [95\% Cl 1.21-2.49]).

Interpretation: We identified ethnic differences in filling of prescriptions for several secondary prevention medications after acute stroke. The reasons underlying these differences need to be investigated.

$\mathrm{P}$ eople of Chinese (originating from China, Taiwan or Hong Kong) and South Asian (originating from India, Pakistan, Bangladesh or Sri Lanka) descent are among the fastest-growing ethnic populations in North America. ${ }^{1-3}$ The burden of stroke and subsequent disability and death in these groups is likewise growing exponentially. ${ }^{4}$ Secondary prevention therapy after acute stroke is a core component of stroke care, essential to reducing the risk of recurrent stroke and death. ${ }^{5,6}$ As such, health care organizations aim to create equitable access to stroke care across all populations regardless of ethnicity.

However, it remains unknown whether there are differences in secondary prevention care after stroke in South Asian and Chinese populations. Studies indicate that South Asian and Chinese patients are less likely to meet targets for vascular risk reduction than their white counterparts. ${ }^{7}$ These groups may also hold a different understanding on vascular disease ${ }^{8,9}$ or may have communication barrier ${ }^{10}$ that affect use of sec- ondary prevention therapies. The aim of this populationbased study was to evaluate potential ethnic differences in secondary prevention pharmacotherapy after acute stroke. Specifically, we compared prescription filling for the guideline-recommended treatments within 1 year after hospital discharge for acute ischemic stroke and the combination of angiotensin-converting-enzyme (ACE) inhibitor and diuretic for primary intracerebral hemorrhagic stroke among South Asian, Chinese and other Canadian patients aged 66 years or more in Ontario and British Columbia.

\section{Competing interests: None declared.}

This article has been peer reviewed.

Correspondence to: Nadia Khan, nakhanubc@gmail.com

CMAJ Open 2017. DOI:10.9778/cmajo.20160147 


\section{Methods}

\section{Setting}

This was a retrospective population-based analysis using administrative data from Ontario (1997-2011) and British Columbia (1997-2009). We selected these 2 provinces as they include the largest nonwhite populations in Canada. ${ }^{1,2}$ The differing time periods reflect the maximally allowable data collection periods for the 2 provinces at the time of data request. To our knowledge, there were no major drug policy changes during 2010-2011 in Ontario.

\section{Data sources}

We used the Discharge Abstract Database, which includes all inpatient records with International Classification of Diseases, 9th revision (ICD-9) and 10th revision (ICD-10) diagnostic codes. The Ontario Drug Benefit and British Columbia's PharmaNet databases contain the Drug Identification Number used to identify all drug claims filled at nonhospital pharmacies. Novel orally administered anticoagulants were approved for atrial fibrillation only in October 2010 and so were not included in this analysis. Data on over-the-counter medications including acetylsalicylic acid were also not available. We obtained deidentified linked health data sets through the Institute for Clinical Evaluative Sciences in Ontario and Population Data BC with approval of relevant data stewards. ${ }^{11}$

\section{Stroke population}

All residents aged 66 years or more discharged alive from hospital after acute ischemic or hemorrhagic stroke were included. Prescription data in Ontario are available only for those aged 65 years or more, and we looked back 6 months to determine medication prescriptions filled before the stroke. We identified stroke cases using validated, most responsible diagnosis coding with a positive predictive value of $85 \%$ or greater for ischemic stroke (ICD-9 434, 436, or ICD-10-CA I63, I64) and primary intracerebral hemorrhage (ICD-9 431 and ICD-10 I61.x). ${ }^{12}$

\section{Pharmacotherapy for secondary prevention}

Among patients with ischemic stroke, as the 2 primary aims, we determined the proportion who filled at least 1 prescription for the optimal medication bundle (diuretic, ACE inhibitor and $\operatorname{statin}^{13,14}$ ) or, if they had atrial fibrillation, warfarin. ${ }^{15}$ The American Heart Association and Hypertension Canada guidelines for secondary prevention therapy of stroke recommend the combination of ACE inhibitor and diuretic as the preferred antihypertensive therapy for both ischemic and hemorrhagic stroke, statins for atherosclerotic ischemic stroke and warfarin in patients with ischemic stroke and atrial fibrillation. ${ }^{13,14}$ As secondary aims, we investigated the combination of any antihypertensive and statin, and individual medications including ACE inhibitors, angiotensin-receptor blockers, diuretics, calcium-channel blockers and $\beta$-blockers. For patients with primary intracerebral hemorrhage, the primary aim was to evaluate prescription filling for the combination of ACE inhibitor and diuretic, and, for the secondary aim, any antihypertensive agent. We determined prescription filling in patients discharged alive and within 1 year of discharge from hospital.

Drug costs may influence the decision to fill a prescription. In Ontario and British Columbia, costs for medications are subsidized for low-income older people. In Ontario, those aged 65 years or more pay a $\$ 100$ deductible each year for medications and $\$ 6.11$, on average, for each approved prescription filled, depending on their income. Those with a low income can have their deductible waived and pay up to $\$ 2$ for each prescription. In British Columbia, an income-based deductible program was initiated in 2003 whereby patients pay a deductible based on income and pay $25 \%$ of medication costs thereafter.

\section{Categorizing ethnicity}

To determine Chinese and South Asian ethnicity, we used Quan and colleagues'16 surname list for Chinese names and the Nam Pehchan surname algorithm for South Asian names. ${ }^{17}$ Intermarriage does not affect the categorization substantially. ${ }^{16}$ The remaining patients were categorized as "other Canadians;" this group encompassed white patients (93\%) and non-Chinese, non-South Asian visible minority groups.

\section{Other baseline characteristics}

We obtained history of prior congestive heart failure, atrial fibrillation, hypertension, diabetes and myocardial infarction from the Discharge Abstract Database using validated ICD coding algorithms at the time of admission for acute stroke. ${ }^{12,18} \mathrm{We}$ assigned socioeconomic status using median neighbourhood income based on each patient's postal code.

\section{Statistical analysis}

We compared categorical variables using the $\chi^{2}$ test and continuous variables using one-way analysis of variance, where appropriate. We constructed hierarchical risk-adjusted logistic regression models for either stroke type to determine the association of ethnicity with prescription filling, adjusting for neighbourhood income quintile, age, sex, most responsible physician (family doctor v. specialist), prior medication use, and history of atrial fibrillation, hypertension, diabetes, dyslipidemia, myocardial infarction or congestive heart failure. We used multilevel modelling to account for potential clustering at the level of province and hospital. All analyses were conducted with SAS version 9.4.

\section{Ethics approval}

The study was approved by the research ethics boards of the University of Toronto and the University of British Columbia.

\section{Results}

There were 108699 patients with acute ischemic stroke and 9663 patients with primary intracerebral hemorrhagic stroke aged 66 years or more. Ischemic stroke was more common than hemorrhagic stroke for all ethnic groups (Chinese $84.1 \%$, South Asian 90.4\%, other Canadians 92.1\%). Of the 108699 patients with ischemic stroke, 2884 were Chinese, 1875 were South Asian, and 103940 were other Canadians. The corresponding values for primary intracerebral hemorrhagic stroke were 546, 200 and 8917. 


\section{OPEN}

Research

\section{Baseline characteristics}

In the ischemic stroke subgroup, both Chinese and South Asian patients were more likely than other Canadian patients to occupy lower socioeconomic status quintiles, to have hypertension, to have diabetes and to be admitted by an Internal Medicine or Neurology (Table 1). Chinese patients were less likely than South Asian or other Canadian patients to fill a prescription for an ACE inhibitor but more likely to fill a prescription for an angiotensin-receptor blocker. However, the proportion of patients filling prescriptions for antihypertensive medications was similar among 3 groups. Among patients with atrial fibrillation, other Canadian patients were more

\begin{tabular}{|c|c|c|c|c|}
\hline \multirow[b]{2}{*}{ Characteristic } & \multicolumn{3}{|c|}{ Ethnicity; no. (\%) of patients } & \multirow[b]{2}{*}{$p$ value } \\
\hline & $\begin{array}{l}\text { Chinese } \\
n=2884\end{array}$ & $\begin{array}{c}\text { Other } \\
\text { Canadians } \\
n=103940\end{array}$ & $\begin{array}{l}\text { South Asian } \\
n=1875\end{array}$ & \\
\hline \multicolumn{5}{|l|}{ Age, yr } \\
\hline $65-74$ & 967 (33.5) & 30490 (29.3) & $815(43.5)$ & $<0.001$ \\
\hline $75-84$ & $1328(46.0)$ & $48468(46.6)$ & $775(41.3)$ & \\
\hline$\geq 85$ & $589(20.4)$ & $24982(24.0)$ & 285 (15.2) & \\
\hline Women & $1592(55.2)$ & $56072(53.9)$ & $943(50.3)$ & 0.003 \\
\hline Live in British Columbia & $1050(36.4)$ & $18677(18.0)$ & $716(38.2)$ & $<0.001$ \\
\hline \multicolumn{5}{|l|}{$\begin{array}{l}\text { Median neighbourhood income } \\
\text { quintile* }^{*}\end{array}$} \\
\hline Q1 (lowest) & $793(27.5)$ & $23755(22.8)$ & $530(28.3)$ & $<0.001$ \\
\hline Q2 & $677(23.5)$ & $22435(21.6)$ & $460(24.5)$ & \\
\hline Q3 & $515(17.8)$ & $20084(19.3)$ & $406(21.6)$ & \\
\hline Q4 & $489(17.0)$ & $18390(17.7)$ & $261(13.9)$ & \\
\hline Q5 (highest) & $386(13.4)$ & $18419(17.7)$ & $208(11.1)$ & \\
\hline Hypertension & $675(23.4)$ & $20598(19.8)$ & $477(25.4)$ & $<0.001$ \\
\hline Diabetes & 337 (11.7) & $8661(8.3)$ & $301(16.0)$ & $<0.001$ \\
\hline Acute myocardial infarction & $76(2.6)$ & $4768(4.6)$ & $75(4.0)$ & $<0.001$ \\
\hline Heart failure & $100(3.5)$ & $5073(4.9)$ & $101(5.4)$ & 0.001 \\
\hline Atrial fibrillation & $363(12.6)$ & 12368 (11.9) & $151(8.0)$ & $<0.001$ \\
\hline \multicolumn{5}{|l|}{ Admitting physician } \\
\hline Family physician & $851(29.5)$ & $55441(53.3)$ & $761(40.6)$ & $<0.001$ \\
\hline Internist & $1291(44.8)$ & 24795 (23.8) & $627(33.4)$ & \\
\hline Neurologist & $455(15.8)$ & $14074(13.5)$ & $322(17.2)$ & \\
\hline Other & $287(10.0)$ & $9630(9.3)$ & $165(8.8)$ & \\
\hline \multicolumn{5}{|l|}{$\begin{array}{l}\text { Medication(s) prescribed in } \\
6 \text { mo before stroke }\end{array}$} \\
\hline ACE inhibitor & $762(26.4)$ & 37309 (35.9) & $687(36.6)$ & $<0.001$ \\
\hline$\beta$-blocker & $840(29.1)$ & 31066 (29.9) & $548(29.2)$ & 0.6 \\
\hline Angiotensin-receptor blocker & $451(15.6)$ & $8662(8.3)$ & $215(11.5)$ & $<0.001$ \\
\hline Calcium-channel blocker & $864(30.0)$ & $28407(27.3)$ & $558(29.8)$ & 0.006 \\
\hline Diuretic & $593(20.6)$ & $32328(31.1)$ & $504(26.9)$ & $<0.001$ \\
\hline Any antihypertensive & 1970 (68.3) & $72111(69.4)$ & $1301(69.4)$ & 0.5 \\
\hline Acetylsalicylic acid & $411(14.2)$ & $14561(14.0)$ & $310(16.5)$ & 0.007 \\
\hline Statin & $631(21.9)$ & $24720(23.8)$ & $557(29.7)$ & $<0.001$ \\
\hline Warfarint & $71(19.6)$ & $3410(27.6)$ & $37(24.5)$ & 0.002 \\
\hline
\end{tabular}


likely to have filled a prescription for warfarin before stroke than Chinese or South Asian patients.

Among patients with primary intracerebral hemorrhagic stroke, South Asian and Chinese patients were more likely than other Canadians to occupy lower socioeconomic status quintiles and to have diabetes (Table 2). Compared to South Asian and other Canadian patients, Chinese patients were more likely to be cared for by specialists rather than family

\begin{tabular}{|c|c|c|c|c|}
\hline \multirow[b]{2}{*}{ Characteristic } & \multicolumn{3}{|c|}{ Ethnicity; no. (\%) of patients } & \multirow[b]{2}{*}{$p$ value } \\
\hline & $\begin{array}{l}\text { Chinese } \\
n=546\end{array}$ & $\begin{array}{c}\text { Other } \\
\text { Canadians } \\
n=8917\end{array}$ & $\begin{array}{l}\text { South Asian } \\
n=200\end{array}$ & \\
\hline \multicolumn{5}{|l|}{ Age, yr } \\
\hline $65-74$ & $197(36.1)$ & $2982(33.4)$ & $89(44.5)$ & 0.01 \\
\hline $75-84$ & $255(46.7)$ & $4186(46.9)$ & $78(39.0)$ & \\
\hline$\geq 85$ & $94(17.2)$ & $1749(19.6)$ & $33(16.5)$ & \\
\hline Women & $289(52.9)$ & $4665(52.3)$ & $102(51.0)$ & 0.9 \\
\hline Live in British Columbia & $220(40.3)$ & $1421(15.9)$ & $71(35.5)$ & $<0.001$ \\
\hline \multicolumn{5}{|l|}{$\begin{array}{l}\text { Median neighbourhood income } \\
\text { quintile* }^{*}\end{array}$} \\
\hline Q1 (lowest) & $152(27.8)$ & $1829(20.5)$ & $59(29.5)$ & $<0.001$ \\
\hline Q2 & $120(22.0)$ & $1890(21.2)$ & $46(23.0)$ & \\
\hline Q3 & $110(20.1)$ & $1747(19.6)$ & $41(20.5)$ & \\
\hline Q4 & $102(18.7)$ & $1679(18.8)$ & 27 (13.5) & \\
\hline Q5 (highest) & $60(11.0)$ & $1705(19.1)$ & $27(13.5)$ & \\
\hline Hypertension & $355(65.0)$ & $6118(68.6)$ & $123(61.5)$ & 0.02 \\
\hline Diabetes & $62(11.4)$ & $830(9.3)$ & $28(14.0)$ & 0.03 \\
\hline Acute myocardial infarction & $21(3.8)$ & $287(3.2)$ & $7(3.5)$ & 0.7 \\
\hline Heart failure & $12(2.2)$ & $267(3.0)$ & $<5(<1.0)$ & 0.2 \\
\hline Atrial fibrillation & $30(5.5)$ & $647(7.2)$ & $<5(<1.0)$ & 0.01 \\
\hline \multicolumn{5}{|l|}{ Admitting physician } \\
\hline Family physician & $149(27.3)$ & $3617(40.6)$ & $65(32.5)$ & $<0.001$ \\
\hline Internist & $196(35.9)$ & $2129(23.9)$ & $50(25.0)$ & \\
\hline Neurologist & $82(15.0)$ & $1360(15.2)$ & $34(17.0)$ & \\
\hline Neurosurgeon & $72(13.2)$ & $1023(11.5)$ & $26(13.0)$ & \\
\hline Other & $47(8.6)$ & $788(8.8)$ & $25(12.5)$ & \\
\hline \multicolumn{5}{|l|}{$\begin{array}{l}\text { Medication(s) prescribed in } \\
6 \text { mo before stroke }\end{array}$} \\
\hline ACE inhibitor & $120(22.0)$ & 2699 (30.3) & $75(37.5)$ & $<0.001$ \\
\hline$\beta$-blocker & $111(20.3)$ & $2120(23.8)$ & $41(20.5)$ & 0.1 \\
\hline Angiotensin-receptor blocker & $68(12.4)$ & $667(7.5)$ & $9(4.5)$ & $<0.001$ \\
\hline Calcium-channel blocker & $122(22.3)$ & $1771(19.9)$ & $34(17.0)$ & 0.2 \\
\hline Diuretic & $81(14.8)$ & $2006(22.5)$ & $38(19.0)$ & $<0.001$ \\
\hline Any antihypertensive agent & $318(58.2)$ & $5181(58.1)$ & $114(57.0)$ & 1.0 \\
\hline Statin & $122(22.3)$ & 2067 (23.2) & $45(22.5)$ & 0.9 \\
\hline Acetylsalicylic acid & $50(9.2)$ & $891(10.0)$ & $30(15.0)$ & 0.05 \\
\hline Warfarin† & $17(56.7)$ & 358 (55.3) & - & 0.3 \\
\hline $\begin{array}{l}\text { Note: } \mathrm{ACE}=\text { angioten-converting-enzyn } \\
{ }^{*} \text { Missing for } 0.7 \% \text { of patients. } \\
\text { †Among patients with atrial fibrillation. }\end{array}$ & & & & \\
\hline
\end{tabular}




\section{OPEN}

Research

physicians. Chinese patients were least likely to have filled prescriptions for antihypertensive therapy before the stroke, whereas South Asians were most likely to have filled such prescriptions.

\section{Pharmacotherapy for secondary prevention}

Unadjusted rates of filling of prescriptions for secondary prevention therapy within 1 year after discharge from hospital after acute stroke are presented in Table 3 and Table 4.

\begin{tabular}{|c|c|c|c|c|}
\hline \multirow[b]{2}{*}{ Medication } & \multicolumn{3}{|c|}{ Ethnicity; no. (\%) of patients } & \multirow[b]{2}{*}{$p$ value } \\
\hline & $\begin{array}{l}\text { Chinese } \\
n=2884\end{array}$ & $\begin{array}{c}\text { Other } \\
\text { Canadians } \\
n=103940\end{array}$ & $\begin{array}{l}\text { South Asian } \\
n=1875\end{array}$ & \\
\hline ACE inhibitor & $1263(43.8)$ & $51528(49.6)$ & $1015(54.1)$ & $<0.001$ \\
\hline Angiotensin-receptor blocker & $574(19.9)$ & $10785(10.4)$ & 269 (14.3) & $<0.001$ \\
\hline $\begin{array}{l}\text { ACE inhibitor or angiotensin- } \\
\text { receptor blocker }\end{array}$ & $1651(57.2)$ & $58611(56.4)$ & $1176(62.7)$ & $<0.001$ \\
\hline Diuretic & $746(25.9)$ & $39651(38.1)$ & $580(30.9)$ & $<0.001$ \\
\hline Calcium-channel blocker & $983(34.1)$ & 32708 (31.5) & $702(37.4)$ & $<0.001$ \\
\hline$\beta$-blocker & $892(30.9)$ & $34439(33.1)$ & $657(35.0)$ & 0.009 \\
\hline ACE inhibitor or diuretic & $1583(54.9)$ & $66196(63.7)$ & $1210(64.5)$ & $<0.001$ \\
\hline ACE inhibitor + diuretic & $426(14.8)$ & $24983(24.0)$ & 385 (20.5) & $<0.001$ \\
\hline Any antihypertensive agent & $2193(76.0)$ & $80138(77.1)$ & $1494(79.7)$ & 0.01 \\
\hline Statin & $1254(43.5)$ & $43550(41.9)$ & $953(50.8)$ & $<0.001$ \\
\hline Statin or ACE inhibitor or diuretic & 1988 (68.9) & $75846(73.0)$ & $1415(75.5)$ & $<0.001$ \\
\hline Statin + ACE inhibitor + diuretic & $231(8.0)$ & $13119(12.6)$ & $254(13.5)$ & $<0.001$ \\
\hline Statin or antihypertensive & $2295(79.6)$ & $83764(80.6)$ & $1551(82.7)$ & 0.03 \\
\hline Statin + antihypertensive & 1152 (39.9) & $39924(38.4)$ & $896(47.8)$ & $<0.001$ \\
\hline Warfarin* & $249(68.6)$ & $9014(72.9)$ & $109(72.2)$ & 0.2 \\
\hline
\end{tabular}

Table 4: Proportions of patients who filled prescriptions for secondary prevention therapy within 1 year after primary intracerebral hemorrhagic stroke by ethnicity

\begin{tabular}{|c|c|c|c|c|}
\hline \multirow[b]{2}{*}{ Medication } & \multicolumn{3}{|c|}{ Ethnicity; no. $(\%)$ of patients } & \multirow[b]{2}{*}{$p$ value } \\
\hline & $\begin{array}{l}\text { Chinese } \\
n=546\end{array}$ & $\begin{array}{c}\text { Other } \\
\text { Canadians } \\
n=8917\end{array}$ & $\begin{array}{l}\text { South Asian } \\
n=200\end{array}$ & \\
\hline ACE inhibitor & $200(36.6)$ & $3924(44.0)$ & $118(59.0)$ & $<0.001$ \\
\hline Angiotensin-receptor blocker & $80(14.6)$ & $827(9.3)$ & $23(11.5)$ & 0.001 \\
\hline $\begin{array}{l}\text { ACE inhibitor or angiotensin- } \\
\text { receptor blocker }\end{array}$ & $252(46.2)$ & $4428(49.6)$ & $127(63.5)$ & 0.001 \\
\hline Diuretic & $109(20.0)$ & $2845(31.9)$ & $57(28.5)$ & $<0.001$ \\
\hline Calcium-channel blocker & $185(33.9)$ & $2716(30.4)$ & $63(31.5)$ & 0.2 \\
\hline$\beta$-blocker & $139(25.4)$ & $2682(30.1)$ & $64(32.0)$ & 0.1 \\
\hline ACE inhibitor or diuretic & $253(46.3)$ & $4942(55.4)$ & $131(65.5)$ & $<0.001$ \\
\hline ACE inhibitor + diuretic & $56(10.2)$ & $1827(20.5)$ & $44(22.0)$ & $<0.001$ \\
\hline Any antihypertensive & $352(64.5)$ & $6125(68.7)$ & $155(77.5)$ & 0.003 \\
\hline
\end{tabular}




\section{Ischemic stroke}

In the ischemic stroke subgroup, filling of prescriptions for statins was relatively low in all groups. Compared to the other groups, Chinese patients were less likely to fill prescriptions for ACE inhibitor and diuretic combination therapy $(p<$ 0.001 ) and for the optimal bundle of ACE inhibitor, diuretic and statin $(p<0.001)$. South Asians were more likely than the 2 other groups to fill prescriptions for any antihypertensive $(p=0.01)$ and for statins $(p<0.001)$, but only 254 South Asians (13.5\%) filled prescriptions for the optimal bundle of diuretic, ACE inhibitor and statin. Only $68.6 \%-72.9 \%$ of patients with atrial fibrillation filled prescriptions for warfarin after ischemic stroke; there was no difference between ethnic groups in the unadjusted analysis $(p=0.2)$.

In the adjusted analysis, there were no differences between groups in prescription filling for any antihypertensive among patients with ischemic stroke (Table 5). However, fewer Chinese patients than other Canadian patients filled prescriptions for the optimal therapy bundle of ACE inhibitor, diuretic and statin (adjusted odds ratio [OR] 0.64 [95\% confidence interval (CI) 0.55-0.74]). Among patients with atrial fibrillation, fewer Chinese patients than other Canadian patients filled prescriptions for warfarin (adjusted OR 0.75 [95\% CI 0.59-0.95]).
There was no difference in prescription filling of the optimal therapy bundle of ACE inhibitor, diuretic and statin between South Asian and other Canadian patients.

\section{Primary intracerebral hemorrhagic stroke}

For patients with primary intracerebral hemorrhagic stroke, the most commonly filled antihypertensive prescription was ACE inhibitor in all groups (Table 4). Antihypertensive prescriptions were filled by $64.5 \%-77.5 \%$ of patients, and few patients filled prescriptions for the optimal combination of ACE inhibitor and diuretic. In the unadjusted analysis, Chinese patients were less likely than South Asian or other Canadian patients to fill any antihypertensive agent prescriptions $(p=0.003)$, including optimal ACE inhibitor and diuretic combination therapy $(p<0.001)$. After adjustment for baseline characteristics, Chinese patients remained less likely than other Canadian patients to fill prescriptions for the optimal combination of ACE inhibitor and diuretic (adjusted OR 0.51 [95\% CI 0.38-0.69]) (Table 5). South Asian patients were more likely than other Canadian patients to fill prescriptions for any antihypertensive agent (adjusted OR 1.73 [95\% CI 1.21-2.49]) and for the optimal combination of ACE inhibitor and diuretic (adjusted OR 1.31 [95\% CI 0.91-1.88]).

\begin{tabular}{|c|c|c|}
\hline \multirow[b]{2}{*}{ Stroke type; medication } & \multicolumn{2}{|c|}{ Adjusted OR $(95 \% \mathrm{Cl})^{*}$} \\
\hline & $\begin{array}{l}\text { Chinese v. other } \\
\text { Canadians }\end{array}$ & $\begin{array}{l}\text { South Asian v. other } \\
\text { Canadians }\end{array}$ \\
\hline \multicolumn{3}{|l|}{ Ischemic } \\
\hline ACE inhibitor or diuretic & $0.70(0.64-0.76)$ & $0.96(0.86-1.06)$ \\
\hline ACE inhibitor + diuretic & $0.63(0.56-0.70)$ & $0.88(0.78-0.99)$ \\
\hline $\begin{array}{l}\text { ACE inhibitor or angiotensin- } \\
\text { receptor blocker }\end{array}$ & $0.97(0.89-1.06)$ & $1.05(0.95-1.16)$ \\
\hline Any antihypertensive & $0.92(0.83-1.02)$ & $1.06(0.93-1.20)$ \\
\hline Statin & $0.97(0.88-1.07)$ & $1.10(0.98-1.24)$ \\
\hline Statin, ACE inhibitor or diuretic & $0.78(0.71-0.86)$ & $0.96(0.85-1.07)$ \\
\hline Statin + ACE inhibitor + diuretic & $0.64(0.55-0.74)$ & $1.01(0.87-1.17)$ \\
\hline Any antihypertensive or statin & $0.89(0.80-0.99)$ & $0.99(0.87-1.14)$ \\
\hline Any antihypertensive + statin & $0.99(0.91-1.09)$ & $1.16(1.03-1.29)$ \\
\hline Warfarin† & $0.75(0.59-0.95)$ & $0.88(0.60-1.28)$ \\
\hline \multicolumn{3}{|l|}{ Primary intracerebral hemorrhagic } \\
\hline ACE inhibitor or diuretic & $0.69(0.57-0.83)$ & $1.64(1.20-2.24)$ \\
\hline ACE inhibitor + diuretic & $0.51(0.38-0.69)$ & $1.31(0.91-1.88)$ \\
\hline $\begin{array}{l}\text { ACE inhibitor or angiotensin- } \\
\text { receptor blocker }\end{array}$ & $0.79(0.65-0.96)$ & $1.75(1.28-2.40)$ \\
\hline Any antihypertensive agent & $0.82(0.67-1.01)$ & $1.73(1.21-2.49)$ \\
\hline \multicolumn{3}{|c|}{$\begin{array}{l}\text { Note: } A C E=\text { angiotensin-converting-enzyme. } \\
{ }^{*} \text { Adjusted for income quintile, age, sex, admitting physician (family physician v. specialist), prior medication } \\
\text { use, and history of atrial fibrillation, hypertension, diabetes, dyslipidemia, myocardial infarction or congestive } \\
\text { heart failure. } \\
\text { †Among patients with atrial fibrillation. }\end{array}$} \\
\hline
\end{tabular}




\section{OPEN}

\section{Interpretation}

Although some prescriptions for secondary prevention therapy were filled by similar proportions of Chinese, South Asian and other Canadian patients, smaller proportions of Chinese patients filled prescriptions for the preferred combination of ACE inhibitor, diuretic and statin, and for anticoagulation therapy for atrial fibrillation following ischemic stroke. Similarly, after primary intracerebral hemorrhagic stroke, Chinese patients were less likely to fill prescriptions for preferred antihypertensive therapy with an ACE inhibitor and a diuretic. South Asian patients, in contrast, were just as likely as or more likely than other Canadian patients to fill prescriptions for secondary prevention treatment after acute ischemic stroke or intracerebral hemorrhagic stroke.

Our study provides new data on secondary prevention treatment among these ethnic groups and extends previous work that focused on other components of stroke care. Xian and colleagues ${ }^{19}$ identified similar or greater provision of inhospital stroke care in Asian populations in the United States: Asian patients with intracerebral hemorrhage had higher odds of receiving deep vein thrombosis prophylaxis and dysphagia screening than white patients. In a previous study of 12 stroke centres in Ontario, we found similar receipt of rehabilitative services, admission to stroke units and brain imaging among ethnic groups. ${ }^{20}$ In contrast, a community-based stroke study in New Zealand showed that Asian patients were less likely than white patients to be using antihypertensive medications before stroke. ${ }^{21}$ Our finding of lower use of some secondary prevention treatments is consistent with studies in hypertension, diabetes and acute myocardial infarction that uniformly showed lower rates of filling of prescriptions for ACE inhibitors in Chinese populations compared to other Canadians. ${ }^{22,23}$

The reasons underlying ethnic differences in filling of prescriptions for secondary prevention treatment are likely multifactorial. There may be differences in health-seeking behaviours in Chinese populations. However, studies indicate that Chinese Canadians are just as likely to visit their family doctor as the general population. ${ }^{24}$ There may also be cultural differences in the patient's willingness to fill prescriptions owing to cost, preference for alternative therapies, mistrust of Western medications ${ }^{25}$ and differing beliefs regarding modifiers of stroke risk. Reasons may also include provider-patient communication barriers ${ }^{10}$ and provider bias. There may be also greater concern by physicians and patients regarding adverse medication side effects in some ethnic groups. Asian patients have been reported to have increased ACE-inhibitor-induced cough compared to other groups. ${ }^{26} \mathrm{In}$ the current study, there was no difference in prescription filling of either ACE inhibitor or angiotensin-receptor blocker (since the latter is a common alternative when patients do not tolerate ACE inhibitor) between Chinese and other Canadian patients in either the ischemic stroke subgroup or the intracerebral hemorrhagic subgroup. Our study also identified considerable underfilling of warfarin prescriptions after ischemic stroke among Chinese patients with atrial fibrillation despite the substantive reductions in recurrent stroke risk with this treatment. There may be reluctance to prescribe anticoagulants to Chinese patients with atrial fibrillation given the potentially higher risk of intracranial hemorrhage with these agents. ${ }^{27}$ More aggressive prescribing in South Asians may reflect health care providers' heightened concern for their high vascular risk.

\section{Strengths and limitations}

A strength of this study is the use of a large, unselected population for analysis of prescription filling for secondary prevention treatment after stroke across 3 ethnic groups. There are also several limitations. First, we used surname algorithms instead of self-reported ethnicity, and the remaining group "other" was heterogeneous, with about $90 \%$ being white. However, surname algorithms are fairly specific, which allowed for conservative estimates of ethnic differences. We did not have information on lipid levels, blood pressure, renal function, severity of stroke or residual deficits. However, previous analysis of patients with acute stroke did not identify any significant difference in baseline blood pressure or stroke severity scores (Canadian Neurological Scale) after acute ischemic stroke or intracerebral hemorrhage in these ethnic groups..$^{20}$ Finally, we were not able to identify medications purchased without a prescription (i.e., acetylsalicylic acid), medications purchased out of province or out of country, and prescriptions that were not filled by patients or, if filled, not consumed.

\section{Conclusion}

Although some prescriptions for secondary prevention treatment were filled to a similar extent across ethnic groups, Chinese patients were less likely than South Asian or other Canadian patients to fill prescriptions for the optimal therapy bundle of ACE inhibitor, diuretic and statin, or for warfarin. The clinical significance of these ethnic differences in provision of secondary prevention treatments is substantial. Combination treatment with an ACE inhibitor and a diuretic is associated with a reduction in recurrent stroke of $43 \%$ and a reduction in vascular events of $40 \% .{ }^{6}$ Warfarin is associated with a reduction of risk of recurrent stroke of $47 \%$ among those with atrial fibrillation. ${ }^{28}$ Statin therapy is associated with a vascular risk reduction of $25 \%$ following stroke. Given the substantial benefits associated with these treatments, there is urgent need to improve secondary medication prescribing and/or primary adherence in stroke populations, especially Canadians of Chinese descent. Further study is needed to understand the causal factors for the lower filling of prescriptions for these secondary prevention treatments among Chinese patients and whether choice of antihypertensive affects recurrent risk of stroke in Asian populations.

\section{References}

1. Canada at a glance 2012. Ottawa: Statistics Canada. Available: www.statcan. gc.ca/pub/12-581-x/2012000/pop-eng.htm (accessed 2017 Feb. 1).

2. 2011 National Household Survey: data tables (modified 2017 Feb. 14). Available: http://www12.statcan.gc.ca/nhs-enm/2011/dp-pd/dt-td/Rp-eng.cfm?LANG=E \&APATH $=3 \& \mathrm{DETAIL}=0 \& \mathrm{DIM}=0 \& \mathrm{FL}=\mathrm{A} \& \mathrm{FREE}=0 \& \mathrm{GC}=0 \& \mathrm{GID}=0 \& \mathrm{GK}=$ $0 \& \mathrm{GRP}=1 \& \mathrm{PID}=105396 \& \mathrm{PRID}=0 \& \mathrm{PTYPE}=105277 \& \mathrm{~S}=0 \& \mathrm{SHOWALL}=0 \&$ $\mathrm{SUB}=0 \&$ Temporal $=2013 \&$ THEME $=95 \& \mathrm{VID}=0 \&$ VNAMEE $\&$ VNAMEF $($ ac cessed 2017 Feb. 1).

3. Hoeffel EM, Rastogi S, Kim MO, et al. The Asian population 2010: 2010 census briefs. Suitland (MD): United States Census Bureau; 2012. Available: www. census.gov/prod/cen2010/briefs/c2010br-11.pdf (accessed 2017 Feb. 1). 
4. Yang G, Wang Y, Zeng Y, et al. Rapid health transition in China, 1990-2010: findings from the Global Burden of Disease Study 2010. Lancet 2013;381:1987-2015.

5. Gueyffier F. Editorial comment - secondary prevention of stroke: beyond meta-analyses. Stroke 2003;34:2748-9.

6. PROGRESS Collaborative Group. Randomised trial of a perindopril-based blood-pressure lowering regimen among 6105 individuals with previous stroke or transient ischaemic attack. Lancet 2001;358:1033-41.

7. Gray J, Millett C, Saxena S, et al. Ethnicity and quality of diabetes care in a health system with universal coverage: population-based cross-sectional survey in primary care. 7 Gen Intern Med 2007;22:1317-20.

8. Webster RA, Thompson DR, Davidson PM. The first 12 weeks following discharge from hospital: the experience of Gujarati South Asian survivors of acute myocardial infarction and their families. Contemp Nurse 2003;15:288-99.

9. King KM, LeBlanc P, Carr W, et al. Chinese immigrants' management of their cardiovascular disease risk. West 7 Nurs Res 2007;29:804-26.

10. Rhodes P, Nocon A. A problem of communication? Diabetes care among Bangladeshi people in Bradford. Health Soc Care Community 2003;11:45-54.

11. BC Ministry of Health Data Stewardship Committee. Consolidation File MSP Registration \& Premium Billing); Discharge Abstracts Database (Hospital Separations) and Medical Services Plan (MSP) Payment Information File; PharmaNet. Population Data BC; BC Ministry of Health; 2012-2014. Available: www.popdata.bc.ca/data (accessed 2017 Feb. 1).

12. Kokotailo RA, Hill MD. Coding of stroke and stroke risk factors using international classification of diseases, revisions 9 and 10. Stroke 2005;36:1776-81.

13. Khan NA, Hemmelgarn B, Herman RJ, et al.; Canadian Hypertension Education Program. The 2009 Canadian Hypertension Education Program recommendations for the management of hypertension: part 2 - therapy. Can 7 Cardiol 2009;25:287-98.

14. Kernan WN, Ovbiagele B, Black HR, et al.; American Heart Association Stroke Council, Council on Cardiovascular and Stroke Nursing, Council on Clinical Cardiology and Council on Peripheral Vascular Disease. Guidelines for the prevention of stroke in patients with stroke and transient ischemic attack: a guideline for healthcare professionals from the American Heart Association/American Stroke Association. Stroke 2014:45:2160-236.

15. Secondary prevention in non-rheumatic atrial fibrillation after transient ischaemic attack or minor stroke. EAFT (European Atrial Fibrillation Trial) Study Group. Lancet 1993;342:1255-62.

16. Quan H, Ghali WA, Dean S, et al. Development and validation of a surname list to define Chinese ethnicity. Med Care 2006;44:328-33.

17. Cummins C, Winter H, Cheng KK, et al. An assessment of the Nam Pehchan computer program for the identification of names of South Asian ethnic origin. 7 Public Health Med 1999;21:401-6.

18. Birman-Deych E, Waterman AD, Yan Y, et al. Accuracy of ICD-9-CM codes for identifying cardiovascular and stroke risk factors. Med Care 2005;43:480-5.

19. Xian Y, Holloway RG, Smith EE, et al. Racial/ethnic differences in process of care and outcomes among patients hospitalized with intracerebral hemorrhage. Stroke 2014:45:3243-50.

20. Khan NA, Quan H, Hill MD, et al. Risk factors, quality of care and prognosis in South Asian, East Asian and other Canadian patients with stroke. BMC Neurol 2013;13:74.

21. Feigin V, Carter K, Hackett M, et al. Ethnic disparities in incidence of stroke subtypes: Auckland Regional Community Stroke Study, 2002-2003. Lancet Neurol 2006;5:130-9.

22. Liu Q, Quan H, Chen G, et al. Antihypertensive medication adherence and mortality according to ethnicity: a cohort study. Can 7 Cardiol 2014;30: 925-31.

23. Lai EJ, Grubisic M, Palepu A, et al. Cardiac medication prescribing and adherence after acute myocardial infarction in Chinese and South Asian Canadian patients. BMC Cardiovasc Disord 2011;11:56.

24. Quan H, Fong A, De Coster C, et al. Variation in health services utilization among ethnic populations. CMA7 2006;174:787-91.
25. Lawton J, Ahmad N, Hallowell N, et al. Perceptions and experiences of taking oral hypoglycaemic agents among people of Pakistani and Indian origin: qualitative study. BM7 2005;330:1247.

26. McDowell SE, Coleman JJ, Ferner RE. Systematic review and meta-analysis of ethnic differences in risks of adverse reactions to drugs used in cardiovascular medicine. BM7 2006;332:1177-81.

27. Hori M, Connolly SJ, Zhu J, et al.; RE-LY Investigators. Dabigatran versus warfarin: effects on ischemic and hemorrhagic strokes and bleeding in Asians and non-Asians with atrial fibrillation. Stroke 2013;44:1891-6.

28. Collins R, Armitage J, Parish S, et al.; Heart Protection Study Collaborative Group. Effects of cholesterol-lowering with simvastatin on stroke and other major vascular events in 20536 people with cerebrovascular disease or other high-risk conditions. Lancet 2004;363:757-67.

Affiliations: Division of General Internal Medicine (Khan, Palepu), University of British Columbia; Centre for Health Evaluation \& Outcomes Sciences (Khan, Palepu), Vancouver, BC; Division of General Internal Medicine (McAlister) and Patient Health Outcomes Research and Clinical Effectiveness Unit (McAlister), University of Alberta, Edmonton, Alta; Divisions of Clinical Epidemiology (Pilote) and General Internal Medicine (Pilote), Department of Medicine, McGill University; The Research Institute of the McGill University Health Centre (Pilote), Montréal, Que.; Departments of Community Health Sciences (Quan, Hill) and Clinical Neurosciences (Hill), University of Calgary, Calgary, Alta.; Institute for Clinical Evaluative Sciences (Fang, Kapral); Division of General Internal Medicine (Kapral), Department of Medicine, University of Toronto, Toronto, Ont.

Contributors: Nadia Khan, Moira Kapral, Hude Quan and Anita Palepu conceived the study. Nadia Khan, Louise Pilote, Michael Hill, Anita Palepu, Finlay McAlister, Hude Quan, and Moira Kapral contributed to the study design. Nadia Khan and Moira Kapral contributed to data collection, and Nadia Khan, Moira Kapral and Jiming Fang contributed to data analysis. All of the authors contributed to interpretation of the data, writing the manuscript and revising the manuscript for important intellectual content, gave final approval of the version to be published and agreed to be accountable for all aspects of the work.

Funding: This study was funded by the Heart and Stroke Foundation of Canada. Nadia Khan receives salary support from the Michael Smith Foundation for Health Research. Hude Quan's and Finlay A. McAlister's salaries are supported by Alberta Innovates - Health Solutions. Moira Kapral was supported by a Career Investigator Award from the Heart and Stroke Foundation of Canada.

Disclaimer: This study was supported by the Institute for Clinical Evaluative Sciences (ICES), which is funded by an annual grant from the Ontario Ministry of Health and Long-Term Care (MOHLTC). The opinions, results and conclusions reported in this article are those of the authors and are independent from the funding sources. No endorsement by the ICES or the Ontario MOHLTC is intended or should be inferred. All inferences, opinions, and conclusions drawn in this report are those of the authors and do not reflect the opinions or policies of Population Data BC.

Supplemental information: For reviewer comments and the original submission of this manuscript, please see www.cmajopen.ca/content $/ 5 / 3$ / E702/suppl/DC1. 